\title{
CORRESPONDENCE
}

To the Editors of The British Journal of Ophthalmology.

SIRS,-I wish to thank Dr. Pines for his kind reference to me in his letter published in your issue of August last. However, it is my duty to point out that there is a very simple explanation for the case he cites as one of acute trachoma.

The history is that the 'emigrant was passed as non-trachomatous' before leaving Poland; he developed an acute inflammation during the voyage to America and was refused admission.

It is obvious that the early signs of quiet trachoma were not recognized before embarkation, and that on the voyage a superimposed Koch-Weeks infection developed, which attracted the attention of the Port Medical Officers.

Even when the examination of a doubtful case of trachoma is made with every optical assistance it may be difficult to make a correct diagnosis; this I experienced last week in the case of a young child with no physical signs except a slight general reddening of the conjunctiva, and trachomatous vascularization of the upper fifth of the corneal periphery, seen only by using the reflected light of the slit-lamp, a phenomenon which I had missed on a previous occasion when seeing this child.

Yours faithfully,

A. F. MacCallan.

33, WELBECK STREET, W. 1

November 14, 1936.

To the Editors of The British Jolral of OpHThalmology.

SIRS,-I read with great interest the paper by Graeme Talbot on pernicious anaemia and retrobulbar neuritis (Brit. Jl. of Ophthal., November, 1936). The cord symptoms of this disease ("myelitis ") are not influenced by liver therapy, but respond well to vitamin B1. The rôle of vitamin B complex in pernicious anaemia was emphasized lately by Karczag. This treatment is indicated in the forementioned case anyhow; it would be highly interesting to note any influence on the optic nerve.

Several papers report successful administration of vitamin B1 in various forms of polyneuritis, pregnancy, toxic, etc. And though personally I had no experience with aneurin, I suggest to try it in various pathological conditions of the optic nerve, e.g., 
inflammations, degeneration. Any improvement in these difficult conditions would be of great value.

Recent papers on this subject are to be found in the Schweiz. Med. Woch., Vol. XLI, pages 977 and 985, further in Brit. Med. Jl. November $\%, 1936$.

Yours faithfully,

STEPHEN DE GRóSZ, M.D.

MáRIA U. 39, BUdAPEST,

HUNGaRY. November 13, 1936.

\section{"POSTERIOR NEEDLING" IN THE TREATMENT OF LAMELLAR AND OTHER FORMS OF SOFT CATARACT}

To the Editors of THE BRITHSH JOURNAL OF OPHTHALMOLOGY.

Sirs,-Dr. Ballantyne's not too severe treatment of my letter on the above subject renders the task of making my final reply comparatively easy.

Dr. Ballantyne does not specify the dates of the textbooks he consulted, but the operative technique in the anterior needling operation has undergone a few modifications in the last 20 years or so, thereby eliminating the uncertainties and complications which have driven him to favour the posterior needling operation.

The term "practically intact capsule" refers to those cases where the opening in the capsule has been too small, so that a certain amount of aqueous fluid has gained access to the interior of the lens and caused some swelling and opacity of the fibres; subsequently the wound in the capsule heals or becomes blocked up so that the swollen lens matter cannot get out and swelling of the lens is produced.

No doubt the experiments performed by Sir John Parsons over 30 years ago were conducted for the purpose which Dr. Ballantyne indicates, but it is the description of the accompanying changes in the vitreous in many cases which has created in me the disinclination to disturb the vitreous through a wound in the sclera, unless absolutely necessary.

Also, I think it is the experience of most ophthalmic surgeons that in penetrating wounds of the eve, one can hold out more favourable prognosis in cases where the injury has not involved the vitreous but has been confined to the anterior part of the 